\title{
Nucleosides XII. ${ }^{1}$ Synthesis of $5^{\prime}$-Modified Isoguanosines and Reinvestigation of $5^{\prime}$-Deoxy- $N^{3}, 5^{\prime}$-cycloisoguanosine
}

\author{
Tun-Cheng Chien ${ }^{\dagger}$ ( 簡敦誠), Chia-Chi Kuo ( 郭佳琦), \\ Chien-Shu Chen ( 陳建樹) and Ji-Wang Chern* (陳基旺) \\ School of Pharmacy, College of Medicine, National Taiwan University, Taipei 100, Taiwan, R.O.C.
}

\begin{abstract}
Isoguanosine (3) underwent a coupling reaction with diaryl disulfides in the presence of tri- $n$-butylphosphine when its 6-amino group was protected by $N, N$-dimethylaminomethylidene. The synthesis of $5^{\prime}$-deoxy$N^{3}, 5^{\prime}$-cycloisoguanosine (6) and its $2^{\prime}, 3^{\prime}$ - $O$-isopropylidene derivative (11) were accomplished in excellent yields from isoguanosines $(\mathbf{3} \& \mathbf{1 0})$ in the presence of triphenylphospine and carbon tetrachloride in pyridine. Chlorination at the $5^{\prime}$-position of isoguanosine (3) with thionyl chloride followed by the aqueous basepromoted cyclization afforded the same product $\mathbf{6}$. The structures were elucidated by spectroscopic analysis including IR, UV, 1-D and 2-D NMR.
\end{abstract}

Keywords: Isoguanosine; Cycloisoguanosine; Chlorination; 5'-Thionucleoside.

\section{INTRODUCTION}

$S$-Adenosyl-L-homocysteine (2, AdoHcy), the byproduct of $S$-adenosyl-L-methionine (AdoMet)-dependent transmethylations, and some of its structural analogs have been shown to be potent competitive inhibitors of the AdoMetdependent methyltransferases. ${ }^{2-4}$ Inhibition of these methyl transfer processes has been correlated with antiviral activity and has attracted considerable attention as a target for the discovery of new antiviral agents. ${ }^{5,6}$ Furthermore, the replacement of the 5'-hydroxyl group with arylthio in certain purine nucleosides resulted in diminishing the alternative substrate activity of purine nucleoside phosphorylases (PNP) and retained or improved the PNP inhibition activity. ${ }^{7}$ Because of these biological properties, a great number of purine nucleoside analogs containing 5 '-sulfur substituents have been synthesized and shown to possess a variety of biological activities. ${ }^{2-4,7-14}$ Our group has also been interested in the synthesis and biological evaluation of several $5^{\prime}$-sulfur containing nucleosides. ${ }^{15-17}$ In continuation of our studies and our longstanding interest in the chemistry and biological activities of isoguanosine derivatives, ${ }^{18-20}$ we initiated a study on $5^{\prime}$-sulfur containing isoguanosine derivatives.

Isoguanosine (3), one of the unique naturally occurring purine nucleosides, was first synthesized by Fischer ${ }^{21}$ and subsequently isolated from plant and animal sources. ${ }^{22-24}$ It is a structural isomer of guanosine and has similar physicochemical properties to guanosine. However, structurally and biologically, isoguanosine (3) and derivatives more resemble adenosine (1) and possess many adenosine-like activities. In the past two decades, our group has been involved in a major research effort to synthesize several isoguanosine derivatives including modifications at $N^{l}, 2^{\prime}$ and $3^{\prime}$-positions and to evaluate their biological activities. ${ }^{18-20}$ To explore the chemical modification of isoguanosine at the 5 '-position, two target structures containing 5 '-sulfur substituents (4 and 5 ) were designed as AdoHcy (2) analogs. Herein, we report the synthesis of nucleosides $\mathbf{4}$ and $\mathbf{5}$, and an unexpected intramolecular cyclization reaction to form the cycloisoguanosine $\mathbf{6}$.

\section{RESULTS AND DISCUSSION}

A convenient preparation of 5'-arylthio-5'-deoxynucleosides was reported by $\mathrm{T}$. Hata et al. involving the reaction of nucleosides with dialkyl disulfides in the presence of tri$n$-butylphosphine in pyridine. ${ }^{8,9}$ In our attempt to synthesize the 5'-arylthio-5'-isoguanosine (4), 3 was treated with bis(4methoxyphenyl) disulfide under Hata's condition, but the desired product (4) was not observed in the reaction. When the reaction was forced to occur with an excess amount of tri- $n$ butylphosphine, only $23 \%$ yield of $N^{6}$-(tri- $n$-butylphosphr-

\footnotetext{
* Corresponding author. Fax: +886-2-2393-4221; e-mail: chern@ jwc.mc.ntu.edu.tw

${ }^{\dagger}$ Current address: Department of Chemistry, The University of Michigan, Ann Arbor, MI 48109, USA
} 


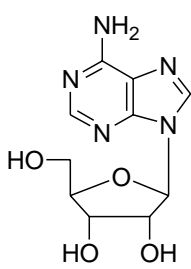

1 adenosine

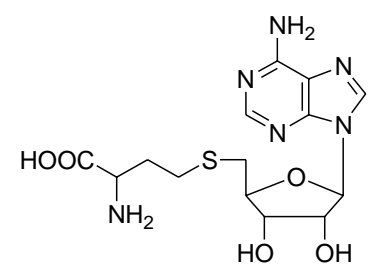

2 S-adenosyl-L-homocysteine (AdoHcy)

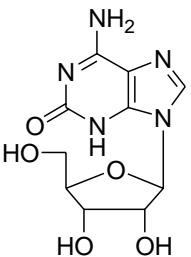

3 isoguanosine

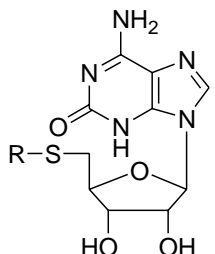

$4 \mathrm{R}=4-\mathrm{MeOPhS}-$

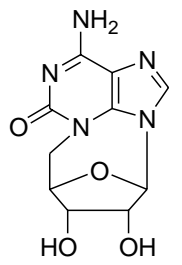

6

$$
5 \mathrm{R}=\mathrm{HOOC}-\stackrel{\mathrm{H}}{\stackrel{\mathrm{I}}{\mathrm{L}}-\mathrm{CH}_{2} \mathrm{CH}_{2} \mathrm{~S}-}
$$

anylidene)-5'-deoxy-5'-[(4-methoxyphenyl)thio]isoguanosine (7) was obtained. An excess amount of tri- $n$-butylphosphine was essential and the reaction was accompanied with the formation of the iminophosphorane at the 6-position.

P. Serafinowski has demonstrated that a suitably protected L-homocystine can be condensed with unprotected nucleosides under Hata's condition to give the protected AdoHcy analogs. ${ }^{11,12}$ However, the attempt to condense $N, N$ bis(trifluoroacetyl)-L-homocystine dimethyl ester ${ }^{1,11,13}$ with isoguanosine (3) under a similar condition was unsuccessful. The preliminary ${ }^{1} \mathrm{H}$ NMR spectra of the only product (6) isolated in $11 \%$ yield showed the absence of the amino acid fragment which suggested that $\mathbf{6}$ is clearly not the expected $N$-trifluoroacetyl- $S$-isoguanosyl-L-homocysteine methyl ester (8a or $\mathbf{8 b}$ ). We subsequently found that $\mathbf{6}$ was also formed in another reaction for the preparation of $5^{\prime}$-chloro-5'-deoxyguanosine (9) from isoguanosine (3) by the phosphine/carbon tetrachloride method. ${ }^{25}$ When isoguanosine (3) was treated with triphenylphosphine and an excess amount of carbon tetrachloride in pyridine, instead of the $5^{\prime}$-chlorinated product (9), 6 was obtained in $75 \%$ yield (Scheme I).

Mass spectrometry suggested that $\mathbf{6}$ is a dehydrated product of isoguanosine (3). The amide-like $N^{3}-\mathrm{H}$ on the base and one of the hydroxy groups on the sugar were absent from the ${ }^{1} \mathrm{H}$ NMR spectrum. This result supported the proposed molecular formula. An infrared absorption peak at $1684 \mathrm{~cm}^{-1}$ indicated the presence of the carbonyl group. The IR spectroscopic data has ruled out the $O^{2}, 5^{\prime}$-cyclization and supported that the substitution occurred at the $N^{3}$-position. Therefore, the structure was unambiguously assigned as 5'-deoxy-

\section{Scheme I}
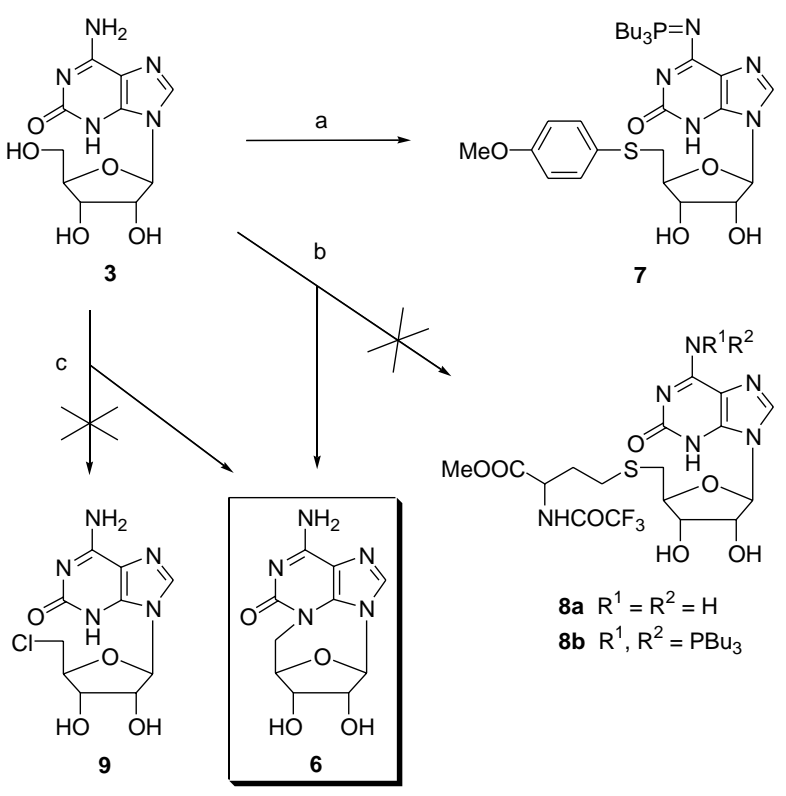

8a $R^{1}=R^{2}=H$

8b $R^{1}, R^{2}=\mathrm{PBu}_{3}$

reagents and conditions

a) 2 eq bis(4-methoxyphenyl) disulfide, 10 eq $n-\mathrm{Bu}_{3} \mathrm{P}$, pyridine, r. t., $12 \mathrm{hr}, 23 \%$

b) 4 eq $N, N$-bis(trifluoroacetyl)-L-homocystine dimethyl ester, 11 eq $n$ - $\mathrm{Bu}_{3} \mathrm{P}$, pyridine, r. t., $24 \mathrm{hr}, 11 \%$

c) 3 eq $\mathrm{Ph}_{3} \mathrm{P}, 3$ eq $\mathrm{CCl}_{4}$, pyridine, r. t., $12 \mathrm{hr}, 75 \%$

$N^{3}, 5^{\prime}$-cycloisoguanosine (6). A perusal of the literature revealed that 6 has been previously reported by F. Seela et al. ${ }^{26}$ However, the ${ }^{1} \mathrm{H}$ NMR data reported by their group is inconsistent with our observations. The discrepancy prompted us to re-examine the structural assignment of $\mathbf{6}$.

A reference compound, $5^{\prime}$-deoxy-2', $3^{\prime}$ - $O$-isopropylidene- $N^{3}, 5^{\prime}$-cycloisoguanosine (11), was prepared by the same route to elucidate the structure of $6.2^{\prime}, 3^{\prime}$-O-Isopropylideneisoguanosine ${ }^{27}(\mathbf{1 0})$ was treated with triphenylphosphine and carbon tetrachloride in pyridine to afford the desired product $\mathbf{1 1}$. The infrared spectrum of $\mathbf{1 1}$ shows a carbonyl absorption peak at $1676 \mathrm{~cm}^{-1}$. K. Anzai previously reported the preparation of $\mathbf{1 1}$ from the $N^{3}, 5^{\prime}$-cyclonucleoside derivative of adenosine. ${ }^{28,29}$ The ${ }^{13} \mathrm{C}$ NMR data that we obtained is identical to Anzai's result, ${ }^{29}$ which confirmed our strucutural assignments. Chlorination at the 5'-position of isoguanosine (3) was accomplished by the procedure reported by F. Seela et al. ${ }^{26}$ The reaction of isoguanosine (3) with thionyl chloride afforded 5'-chloro-5'-deoxyguanosine (9). Potassium carbonate promoted the cyclization of 9 to give a product that was confirmed to be identical to $6 .{ }^{26} \mathrm{O}^{2}, 5^{\prime}$-Cycloisoguanosine was not observed in these reactions (Scheme II).

It is of interest to note that the geminal protons at the 5 '-position of $\mathbf{6}$ exhibited remarkably different chemical 


\section{Scheme II}

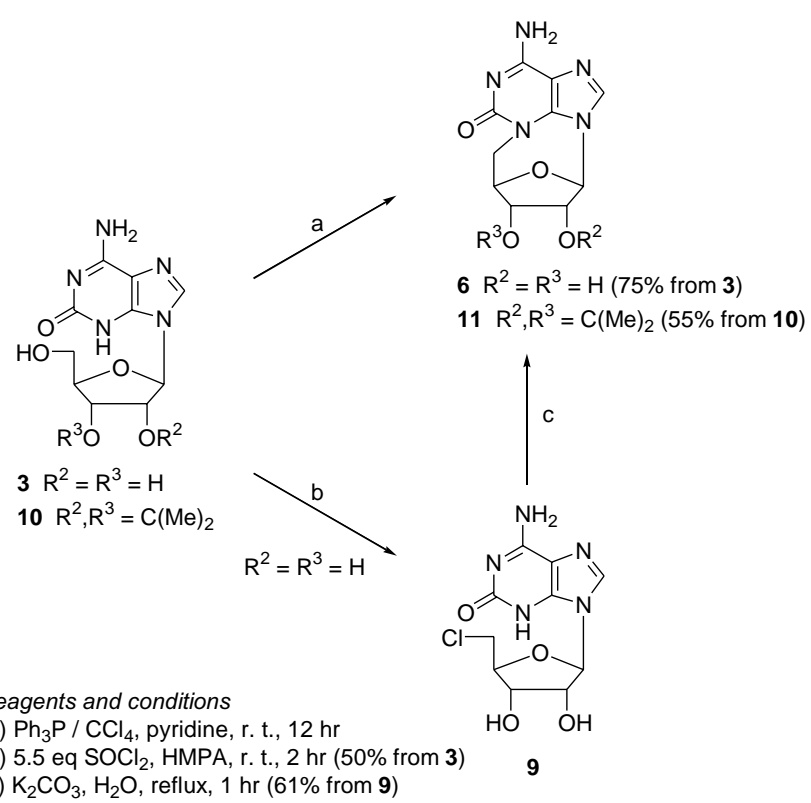

shifts. One of the $5^{\prime}$-protons $\left(5^{\prime}-\mathrm{H}_{\mathrm{a}}\right)$ appeared upfield at 3.76 ppm while the other $5^{\prime}$-proton $\left(5^{\prime}-\mathrm{H}_{\mathrm{b}}\right)$ was shifted considerably downfield to $4.58 \mathrm{ppm}$. In contrast, F. Seela et al. re- ported that the two protons at the $5^{\prime}$-position possess the same chemical shift at $3.87 \mathrm{ppm}$. A similar trend was observed for 11 where the $5^{\prime}$-protons appeared at 3.56 and $4.75 \mathrm{ppm}$. The assignments were verified by COSY and HETCOR NMR spectroscopic studies. The 1-D NOE irradiation of the cycloisoguanosines (6 and 11) at $1^{\prime}-\mathrm{H}(\delta 6.20 \& 6.40$, respectively) showed NOE enhancements at $8-\mathrm{H}(\delta 7.92 \& 7.83$, respectively) and vice versa. The NOE studies indicated that $\mathbf{6}$ and 11 exist in the syn conformation (Table 1).

The synthesis of 5'-arylthio-5'-deoxyisoguanosine was accomplished by an improved procedure. ${ }^{1}$ To avoid the formation of iminophosphorane, the 6-amino group of isoguanosine (3) was first protected with $N, N$-dimethylformamide dimethyl acetal, ${ }^{20}$ then reacted with bis(4-methoxyphenyl) disulfide under Hata's condition to form the desired product 13. Compound 13, without purification, was immediately treated with ammonium hydroxide to remove the protecting group to give 5'-deoxy-5'-[(4-methoxyphenyl)thio]isoguanosine (4). Attempts to purify $\mathbf{4}$ by recrystallization were unsuccessful due to the strong tendency of self-aggregation. ${ }^{27}$ Consequently, 4 was acetylated by acetic anhydride in pyridine to afford $\mathbf{1 4}$ for characterization (Scheme III).

Table 1. NOE effects of compounds $\mathbf{6}$ and $\mathbf{1 1}$

\begin{tabular}{ccccc} 
compound & proton & chemical shift & \multicolumn{2}{c}{ NOE effect } \\
\cline { 2 - 6 } & & & & \\
irradiated at 8-H irradiated at 1'-H
\end{tabular}

\section{Scheme III}

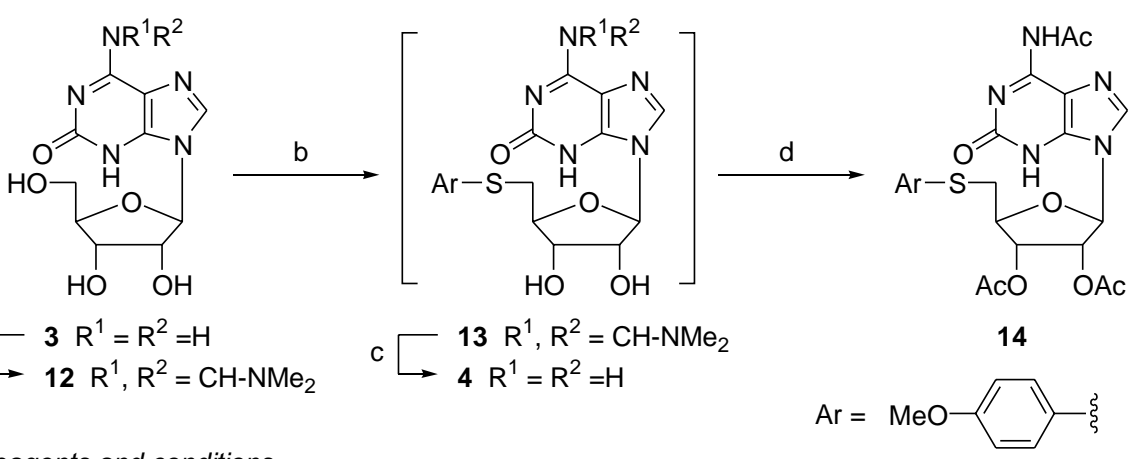

reagents and conditions

a) N,N-dimethylformamide dimethyl acetal, DMF, r. t., $24 \mathrm{hr}$

b) bis(4-methoxyphenyl) disulfide, 10 eq $n$-Bu 3 P, pyridine / DMF, r. t., $24 \mathrm{hr}$

c) $\mathrm{NH}_{3} / \mathrm{MeOH}$, r. t., $24 \mathrm{hr}$

d) $\mathrm{Ac}_{2} \mathrm{O}$, pyridine, r. t., $24 \mathrm{hr}, 30 \%$ (recrystallization) from isoguanosine (3) 


\section{CONCLUSION}

Conformational restriction is a very useful tool for studying the relationship between molecular topography and biochemical or medicinal activities of nucleosides. Our attempts to synthesize the 5'-alkylthio- and 5'-chloro-5'-deoxyisoguanosines led to an unexpected intramolecular cyclization reaction to form the cycloisoguanosine $\mathbf{6}$. This synrestricted cyclic nucleoside (6), along with the anti-restricted cyclic nucleoside (15) previously synthesized by our group, ${ }^{17}$ may be of interest as conformationally rigid adenosine models and useful structural probes to explore their interaction with biological targets.
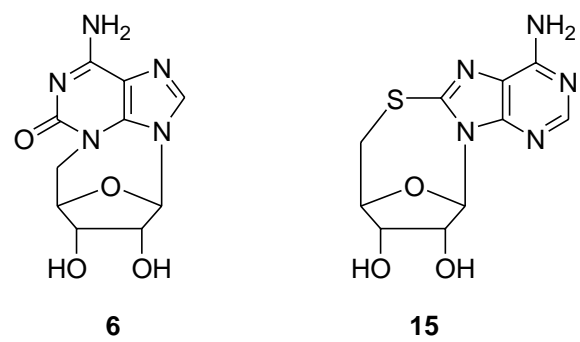

Our investigation has also provided a feasible synthesis of 5'-arylthio- and 5'-chloro-5'-deoxyisoguanosines (4 and 9). Further studies of its applications are under investigation.

\section{EXPERIMENTAL SECTION}

\section{General Chemical Procedures}

Melting points were obtained on an Electrothermal apparatus and are uncorrected. NMR spectra were obtained with Varian Gemini-300, JEOL JNM-EX400 or Bruker DRX500 spectrometer. IR spectra were recorded on a Jasco A-100 infrared spectrophotometer. UV absorption spectra were recorded on a Hitachi U-2001 spectrophotometer. Mass spectra were recorded on Finnigan TSQ-46C (EI), JEOL JMS-D300 (EI), VG 70-250S (FAB) or Micromass LCT (ESI) mass spectrometers. Elemental analyses for $\mathrm{C}, \mathrm{H}$, and $\mathrm{N}$ were carried out either on a Heraeus elemental analyzer or PerkinElmer 240 elemental analyzer and were within $\pm 0.4 \%$ of the theoretical values. Thin-layer chromatography (TLC) was performed on Merck plates precoated with silica gel 60 containing fluorescent indicator. Compounds on thin-layer chromatography were visualized by illumination under UV light (254 nm), or dipped into 10\% methanolic sulfuric acid followed by charring on a hot plate. Solvent systems are expressed as a percentage of the more polar component with re- spect to total volume (v/v\%). Merck silica gel (230-400 mesh) was used for flash column chromatography as described by Still, W. C. et al. ${ }^{30}$ Evaporation was carried out with a rotary evaporator under reduced pressure with the bath temperature below $50{ }^{\circ} \mathrm{C}$ unless specified otherwise. Materials obtained from commercial suppliers were used without further purification. The reported yields have not been optimized.

\section{$5^{\prime}$-Deoxy- $N^{3}, 5^{\prime}$-cycloisoguanosine (6)}

The preparation of $\mathbf{6}$ has been included in our previous paper. ${ }^{31} \mathrm{mp} 249-252{ }^{\circ} \mathrm{C}$ (dec.); ${ }^{1} \mathrm{H}$ NMR (DMSO- $d_{6}, 500$ $\mathrm{MHz}) \delta 8.36(\mathrm{bs}, 1 \mathrm{H}, \mathrm{NH}), 8.07$ (bs, $1 \mathrm{H}, \mathrm{NH}), 7.92(\mathrm{~s}, 1 \mathrm{H}$, $8-\mathrm{H}), 6.20$ (s, 1H, 1'-H), 5.57 (bs, 2H, $2 \times \mathrm{OH}), 4.58(\mathrm{~d}, 1 \mathrm{H}, J$ $\left.=15.0 \mathrm{~Hz}, 5^{\prime}-\mathrm{H}_{\mathrm{a}}\right), 4.57\left(\mathrm{~d}, 1 \mathrm{H}, J=4.5 \mathrm{~Hz}, 4^{\prime}-\mathrm{H}\right), 4.17(\mathrm{t}, 1 \mathrm{H}, J$ $\left.=4.6 \mathrm{~Hz}, 3^{\prime}-\mathrm{H}\right), 3.91\left(\mathrm{~d}, 1 \mathrm{H}, J=5.4 \mathrm{~Hz}, 2^{\prime}-\mathrm{H}\right), 3.76(\mathrm{dd}, 1 \mathrm{H}, J$ $\left.=15.1 \& 3.2 \mathrm{~Hz}, 5^{\prime}-\mathrm{H}_{\mathrm{b}}\right) ;{ }^{13} \mathrm{C}$ NMR (DMSO- $\left.d_{6}, 125 \mathrm{MHz}\right) \delta$ 157.0, 153.9, 142.6, 135.7 (8-CH), 113.3, 93.4 (1'-CH), 84.3 (4'-CH), 76.4 (2'-CH), $71.1\left(3^{\prime}-\mathrm{CH}\right), 52.8\left(5^{\prime}-\mathrm{CH}_{2}\right)$; IR ( $\mathrm{KBr}$, $\left.\mathrm{cm}^{-1}\right) 3365,3202,1717,1684,1662,1616,1591,1560$. UV $\lambda_{\max } \mathrm{nm}(\varepsilon): \mathrm{pH} 1: 237$ (8718), 285 (17120); $\mathrm{H}_{2} \mathrm{O}: 209$ (11952), 280 (6863); pH 11: 279 (10544). MS (EI, $20 \mathrm{eV}) \mathrm{m} / z$ $265\left(\mathrm{M}^{+}\right)$; Anal. Calcd for $\mathrm{C}_{10} \mathrm{H}_{11} \mathrm{~N}_{5} \mathrm{O}_{4} \cdot \mathrm{H}_{2} \mathrm{O}$ : C, 42.41; $\mathrm{H}$, 4.63; N, 24.73. Found: C, 42.43; H, 4.42; N, 24.52.

\section{2',3'-O-Isopropylidene-5' -deoxy- $N^{3}, 5^{\prime}$-cycloisoguanosine} (11)

To a solution of triphenylphosphine $(0.586 \mathrm{~g}, 2.24$ mmol, $2.1 \mathrm{eq})$ in anhydrous pyridine $(21 \mathrm{~mL})$ was added $2^{\prime}, 3^{\prime}$-O-isopropylideneisoguanosine ${ }^{27}(\mathbf{1 0}, 0.344 \mathrm{~g}, 1.06$ $\mathrm{mmol})$. The suspension mixture was stirred at room temperature for $10 \mathrm{~min}$, and then carbon tetrachloride $(1.0 \mathrm{~mL}, 1.64 \mathrm{~g}$, $10.6 \mathrm{mmol}, 10 \mathrm{eq}$ ) was added. The resulting mixture was stirred for an additional $12 \mathrm{hr}$. The solvent was evaporated under reduced pressure. Ethanol $(30 \mathrm{~mL})$ was added to the residue, and a white precipitate of $11(0.178 \mathrm{~g}, 0.583 \mathrm{mmol}$, $55 \%$ ) was obtained. An analytical sample of $\mathbf{1 1}$ was obtained by recrystallization from ethanol. mp $322-330{ }^{\circ} \mathrm{C}$ (dec.) (EtOH); ${ }^{1} \mathrm{H}$ NMR (DMSO- $\left.d_{6}, 500 \mathrm{MHz}\right) \delta 7.83$ (s, $\left.1 \mathrm{H}, 8-\mathrm{H}\right)$, 7.50 (bs, $\left.2 \mathrm{H}, \mathrm{NH}_{2}\right), 6.40$ (s, $\left.1 \mathrm{H}, 1^{\prime}{ }^{\prime}-\mathrm{H}\right), 4.83(\mathrm{t}, 1 \mathrm{H}, J=2.5 \mathrm{~Hz}$, $\left.4^{\prime}-\mathrm{H}\right), 4.76(\mathrm{~d}, 1 \mathrm{H}, J=5.8 \mathrm{~Hz}), 4.75(\mathrm{dd}, 1 \mathrm{H}, J=15.0 \& 2.4$ $\left.\mathrm{Hz}, 5^{\prime}-\mathrm{H}_{\mathrm{a}}\right), 4.45(\mathrm{~d}, 1 \mathrm{H}, J=5.8 \mathrm{~Hz}), 3.56(\mathrm{dd}, 1 \mathrm{H}, J=15.1 \&$ $\left.2.8 \mathrm{~Hz}, 5^{\prime}-\mathrm{H}_{\mathrm{b}}\right), 1.45\left(\mathrm{~s}, 3 \mathrm{H}, \mathrm{CH}_{3}\right), 1.24\left(\mathrm{~s}, 3 \mathrm{H}, \mathrm{CH}_{3}\right) ;{ }^{13} \mathrm{C} \mathrm{NMR}$ (DMSO- $\left.d_{6}, 125 \mathrm{MHz}\right) \delta 159.3,156.3,142.8,134.1(8-\mathrm{CH})$, 114.1, 113.0, 90.8 (1'-CH), $86.2(\mathrm{CH}), 85.4\left(4^{\prime}-\mathrm{CH}\right), 81.4$ $(\mathrm{CH}), 51.6\left(5^{\prime}-\mathrm{CH}_{2}\right), 26.7\left(\mathrm{CH}_{3}\right), 25.2\left(\mathrm{CH}_{3}\right)$; IR $\left(\mathrm{KBr}, \mathrm{cm}^{-1}\right)$ 3284, 3107, 2980, 1676, 1626, 1581; UV $\lambda_{\max } \mathrm{nm}(\varepsilon): \mathrm{pH} 1$ : 237 (6891), 289 (9704); $\mathrm{MeOH} / \mathrm{H}_{2} \mathrm{O}: 280$ (10413); pH 11: 
279 (11983). MS (EI, $70 \mathrm{eV}) \mathrm{m} / z 151$ (42), 305 (100) $\left(\mathrm{M}^{+}\right)$; HRMS (EI) Calcd for $\mathrm{C}_{13} \mathrm{H}_{15} \mathrm{~N}_{5} \mathrm{O}_{4}\left(\mathrm{M}^{+}\right)$: 305.1124, Found: 305.1127; Anal. Calcd for $\mathrm{C}_{13} \mathrm{H}_{15} \mathrm{~N}_{5} \mathrm{O}_{4}$ : C, 51.14; H, 4.95; N, 22.94. Found: C, 51.01; H, 4.92; N, 22.78.

\section{$N^{6}$-(Tri- $n$-butylphosphoranylidene)-5' -deoxy-5' -[(4-meth- oxyphenyl)thio]isoguanosine (7)}

To a mixture of isoguanosine ${ }^{18}(3,0.50 \mathrm{~g}, 1.77 \mathrm{mmol})$ and bis(4-methoxyphenyl) disulfide (1.47 g, $5.30 \mathrm{mmol}, 3$ eq) in a mixture of dry pyridine $(15 \mathrm{~mL})$ and $\mathrm{DMF}(10 \mathrm{~mL})$ was added tri- $n$-butylphosphine $(4.4 \mathrm{~mL}, 3.57 \mathrm{~g}, 17.65 \mathrm{mmol}$, $10 \mathrm{eq}$ ) via a syringe. The reaction was stirred for $24 \mathrm{hr}$ at room temperature under nitrogen, then the solvents were evaporated under reduced pressure. The residue was purified by column chromatography $\left(\mathrm{CHCl}_{3} / \mathrm{MeOH}=92.5: 7.5, \mathrm{Rf}=\right.$ 0.22 ) to give 7 (oil, $0.31 \mathrm{~g}, 0.50 \mathrm{mmol}, 29 \%$ ). Compound 7 was characterized by ${ }^{1} \mathrm{H} \mathrm{NMR} .{ }^{1} \mathrm{H} \mathrm{NMR}\left(\mathrm{CDCl}_{3}, 300 \mathrm{MHz}\right) \delta$ 9.45 (bs, 1H, NH), 7.77 (s, 1H, 8-H), 7.46 (d, 2H, $J=8.7 \mathrm{~Hz}$, $\mathrm{Ph}), 6.84$ (d, 2H, $J=8.7 \mathrm{~Hz}, \mathrm{Ph}), 6.30(\mathrm{~m}, 2 \mathrm{H}, \mathrm{OH}), 5.99$ (s, $\left.1 \mathrm{H}, 1^{\prime}-\mathrm{H}\right), 4.41-4.36(\mathrm{~m}, 2 \mathrm{H}), 3.98(\mathrm{dd}, 1 \mathrm{H}, J=8.0$ \& $4.6 \mathrm{~Hz})$, 3.79 (s, $\left.3 \mathrm{H}, \mathrm{CH}_{3}\right), 3.44$ (dd, $\left.1 \mathrm{H}, J=14.0 \& 3.2 \mathrm{~Hz}, 5^{\prime}-\mathrm{H}\right), 3.15$ (dd, $\left.1 \mathrm{H}, J=14.0 \& 7.0 \mathrm{~Hz}, 5^{\prime}-\mathrm{H}\right), 2.33-2.26\left(\mathrm{~m}, 6 \mathrm{H}, \mathrm{CH}_{2}\right)$, 1.75-1.34 (m, 12H, $\left.\mathrm{CH}_{2}\right), 0.96-0.85\left(\mathrm{~m}, 9 \mathrm{H}, \mathrm{CH}_{3}\right)$.

\section{$N^{6}$-[(Dimethylamino)methylene $]-5^{\prime}-$ deoxy-5' $-[(4-m e t h o x y-$ phenyl)thio]isoguanosine (13)}

To a suspension of isoguanosine $(3,1.49 \mathrm{~g}, 5.26 \mathrm{mmol})$ in DMF (27 mL) was added $N, N$-dimethylformamide dimethyl acetal ( $2.5 \mathrm{~mL}, 2.24 \mathrm{~g}, 18.75 \mathrm{mmol}, 3.6 \mathrm{eq})$. The reaction mixture was stirred at room temperature under nitrogen for $24 \mathrm{hr}$. The solvent was evaporated in vacuo and chloroform $(40 \mathrm{~mL})$ was added. The mixture was stirred vigorously at room temperature for $20 \mathrm{~min}$. The precipitate was collected by filtration to give the crude product $12 .{ }^{20}$ To the crude product 12 and bis(4-methoxyphenyl) disulfide (3.30 g, 11.87 mmol, 2.2 eq $)$ in dry pyridine $(27 \mathrm{~mL})$ was added tri- $n$-butylphosphine (2.4 mL, $1.92 \mathrm{~g}, 9.47 \mathrm{mmol}, 1.8 \mathrm{eq})$ via a syringe. The reaction was stirred for $24 \mathrm{hr}$ at room temperature under nitrogen, then the solvent was evaporated under reduced pressure. Hexane $(30 \mathrm{~mL})$ was added to the resulting oil and the mixture was stirred vigorously at room temperature for 15 min. The precipitate was collected by filtration to give the crude product 13. Compound $\mathbf{1 3}$ was characterized by ${ }^{1} \mathrm{H}$ NMR and was used without further purification. ${ }^{1} \mathrm{H}$ NMR (DMSO-d, $300 \mathrm{MHz}) \delta 11.09$ (bs, 1H, NH), 9.16 (s, 1H, $-\mathrm{CH}=\mathrm{N}), 8.06$ (s, 1H, 8-H), 7.36 (d, 2H, J=8.7 Hz, Ph), 6.89 (d, 2H, $J=8.7 \mathrm{~Hz}, \mathrm{Ph}), 5.67$ (d, 1H, $\left.J=6.0 \mathrm{~Hz}, 1^{\prime}-\mathrm{H}\right), 5.49$ (d,
$1 \mathrm{H}, J=6.1 \mathrm{~Hz}, \mathrm{OH}), 5.31(\mathrm{~d}, 1 \mathrm{H}, J=5.0 \mathrm{~Hz}, \mathrm{OH}), 4.68(\mathrm{dd}$, $1 \mathrm{H}, J=11.3 \& 5.7 \mathrm{~Hz}), 4.09(\mathrm{dd}, 1 \mathrm{H}, J=8.4 \& 4.7 \mathrm{~Hz}), 3.89$ $(\mathrm{dt}, 1 \mathrm{H}, J=6.4 \& 3.3 \mathrm{~Hz}), 3.75\left(\mathrm{~s}, 3 \mathrm{H}, \mathrm{CH}_{3}\right), 3.21(\mathrm{~s}, 3 \mathrm{H}$, $\left.\mathrm{CH}_{3}\right), 3.10$ (s, 3H, $\left.\mathrm{CH}_{3}\right), 3.20-3.10\left(\mathrm{~m}, 2 \mathrm{H}, 5^{\prime}-\mathrm{H}\right)$.

\section{5'-Deoxy-5'-[(4-methoxyphenyl)thio]isoguanosine (4)}

A solution of the crude product $\mathbf{1 3}$ in methanolic ammonia ( $40 \mathrm{~mL}$ ) was stirred at room temperature for $24 \mathrm{hr}$. The precipitate was collected by filtration to give the crude product 4 . Compound 4 was characterized by ${ }^{1} \mathrm{H}$ NMR and was used without further purification. ${ }^{1} \mathrm{H}$ NMR (DMSO- $d_{6}, 200$ $\mathrm{MHz}) \delta 7.94$ (s, 1H, 8-H), 7.36 (d, 2H, $J=8.8 \mathrm{~Hz}, \mathrm{Ph}), 6.89$ (d, $2 \mathrm{H}, J=8.8 \mathrm{~Hz}, \mathrm{Ph}), 5.65$ (d, $\left.1 \mathrm{H}, J=6.0 \mathrm{~Hz}, 1^{\prime}-\mathrm{H}\right), 4.65-$ $4.60(\mathrm{~m}, 1 \mathrm{H}), 4.10-4.05(\mathrm{~m}, 1 \mathrm{H}), 4.00-3.83(\mathrm{~m}, 1 \mathrm{H}), 3.73$ (s, $3 \mathrm{H}, \mathrm{OCH}_{3}$ ), 3.17 (bs, $\left.2 \mathrm{H}, 5^{\prime}-\mathrm{H}\right)$.

\section{$N^{6}-2^{\prime}, 3^{\prime}-O$-Triacetyl-5'-deoxy-5'-[(4-methoxyphenyl)thio]- isoguanosine (14)}

To the suspension of the crude product $\mathbf{4}$ in dry pyridine $(40 \mathrm{~mL})$ was added acetic anhydride $(1.5 \mathrm{~mL}, 1.61 \mathrm{~g}, 15.78$ $\mathrm{mmol}, 3 \mathrm{eq}$ ) and the reaction mixture was stirred at room temperature for $24 \mathrm{hr}$. The solvent was evaporated and the residue was purified by flash column chromatography $\left(\mathrm{CHCl}_{3} / \mathrm{MeOH}=98.5: 1.5\right)$ to give the crude product as an oil. The oil was crystallized in EtOAc to give 14 (0.84 g, 1.58 mmol, 30\% from isoguanosine). $\mathrm{mp} 231-233{ }^{\circ} \mathrm{C}$ (dec.) (EtOAc); ${ }^{1} \mathrm{H}$ NMR $\left(\mathrm{CDCl}_{3}, 300 \mathrm{MHz}\right) \delta 11.83$ (bs, $\left.1 \mathrm{H}, \mathrm{NH}\right)$, 11.16 (bs, 1H, NH), 7.86 (s, 1H, 8-H), 7.36 (d, 2H, $J=8.8 \mathrm{~Hz}$, $\mathrm{Ph}), 6.81(\mathrm{~d}, 2 \mathrm{H}, J=8.8 \mathrm{~Hz}, \mathrm{Ph}), 6.08(\mathrm{~d}, 1 \mathrm{H}, J=6.0 \mathrm{~Hz}$, $\left.1^{\prime}-\mathrm{H}\right), 5.78(\mathrm{t}, 1 \mathrm{H}, J=5.8 \mathrm{~Hz}), 5.46(\mathrm{dd}, 1 \mathrm{H}, J=5.5 \& 4.1 \mathrm{~Hz})$, $4.33(\mathrm{dd}, 1 \mathrm{H}, J=9.1 \& 5.0 \mathrm{~Hz}), 3.77\left(\mathrm{~s}, 3 \mathrm{H}, \mathrm{OCH}_{3}\right), 3.29$ (dd, $\left.1 \mathrm{H}, J=14.3 \& 5.1 \mathrm{~Hz}, 5^{\prime}-\mathrm{H}\right), 3.22(\mathrm{dd}, 1 \mathrm{H}, J=14.3 \& 5.6 \mathrm{~Hz}$, 5'-H), 2.39 (s, 3H, $\left.\mathrm{CH}_{3}\right), 2.09$ (s, 3H, $\left.\mathrm{CH}_{3}\right), 2.03$ (s, 3H, $\left.\mathrm{CH}_{3}\right)$; ${ }^{13} \mathrm{C} \mathrm{NMR}\left(\mathrm{CDCl}_{3}, 75 \mathrm{MHz}\right) \delta 173.7(\mathrm{C}=\mathrm{O}), 170.4(\mathrm{C}=\mathrm{O})$, $170.3(\mathrm{C}=\mathrm{O}), 159.9,159.1,155.2,144.8,141.7,134.0,125.7$, 115.4, 110.2, 85.1 (1'-C), 82.0, 73.5, 72.8, $55.9\left(\mathrm{CH}_{3}\right), 39.0$ $\left(5^{\prime}-\mathrm{CH}_{2}\right), 25.1\left(\mathrm{CH}_{3}\right), 21.2\left(\mathrm{CH}_{3}\right), 21.1\left(\mathrm{CH}_{3}\right)$; MS (FAB) $\mathrm{m} / z$ 133 (100), 291, 381, 532 (45) $\left(\mathrm{M}^{+}+1\right)$; HRMS (FAB) Calcd for $\mathrm{C}_{23} \mathrm{H}_{26} \mathrm{~N}_{5} \mathrm{O}_{8} \mathrm{~S}\left(\mathrm{M}^{+}+1\right)$ : 532.1502, Found: 532.1502; Anal. Calcd for $\mathrm{C}_{23} \mathrm{H}_{25} \mathrm{~N}_{5} \mathrm{O}_{8} \mathrm{~S} \cdot 0.25 \mathrm{H}_{2} \mathrm{O}: \mathrm{C}, 51.54 ; \mathrm{H}, 4.79 ; \mathrm{N}$, 13.06. Found: C, 51.55; H, 5.02; N, 12.84 .

\section{ACKNOWLEDGMENTS}

This investigation was supported by a research grant (NSC84-2331-B-016-018) from the National Science Coun- 
cil of Taiwan.

Received May 4, 2004.

\section{REFERENCES}

1. The previous paper in the series: Chien, T.-C.; Chen, C.-S.; Yu, F.-H.; Chern, J.-W. Chem. Pharm. Bull. 2004 (in press).

2. Chang, C. D.; Coward, J. K. J. Med. Chem. 1976, 19, 684.

3. Borchardt, R. T.; Wu, Y. S.; Wu, B. S. J. Med. Chem. 1978, 21, 1307.

4. Montgomery, J. A.; Thomas, H. J.; Thorpe, M. C.; Chiang, P. K. J. Med. Chem. 1981, 24, 1514.

5. De Clercq, E.; Cools, M. Biochem. Biophys. Res. Commun. 1985, 129, 306.

6. Wolfe, M. S.; Borchardt, R. T. J. Med. Chem. 1991, 34, 1521.

7. Wnuk, S. F.; Stoeckler, J. D.; Robins, M. J. Nucleosides Nucleotides 1994, 13, 389.

8. Nakagawa, I.; Hata, T. Tetrahedron Lett. 1975, 1409.

9. Nakagawa, I.; Aki, K.; Hata, T. J. Chem. Soc. Perkin Trans I 1983, 1315.

10. Shire, D.; Blanchard, P.; Raies, A.; Lawrence, F.; Robertgero, M.; Lederer, E. Nucleosides Nucleotides 1983, 2,21 .

11. Serafinowski, P. Synthesis 1985, 926.

12. Serafinowski, P.; Dorland, E.; Harrap, K. R.; Balzarini, J.; De Clercq, E. J. Med. Chem. 1992, 35, 4576.

13. Johnson, C. R.; Esker, J. L.; Van Zandt, M. C. J. Org. Chem. 1994, 59, 5854.

14. Pignot, M.; Pljevaljcic, G.; Weinhold, E. Eur. J. Org. Chem. 2000, 549.
15. Chern, J.-W.; Lee, H.-Y. J. Chin. Chem. Soc. (Taipei) 1987, 34, 329.

16. Chern, J.-W.; Lee, H.-Y.; Chen, C.-S.; Shewach, D. S.; Daddona, P. E.; Townsend, L. B. J. Med. Chem. 1993, 36, 1024.

17. Chern, J.-W.; Kuo, C.-C.; Chang, M.-J.; Liu, L.-T. Nucleosides Nucleotides 1993, 12, 941.

18. Chern, J.-W.; Lin, G.-S.; Chen, C.-S.; Townsend, L. B. J. Org. Chem. 1991, 56, 4213.

19. Chern, J.-W.; Lin, G.-S.; Chen, C.-S. J. Chin. Chem. Soc. (Taipei) 1992, 39, 347.

20. Chen, C.-S.; Chern, J.-W. Nucleosides Nucleotides 1996, 15 , 1253.

21. Fischer, E. Ber. Dtsch. Chem. Ges. 1897, 30, 2226.

22. Cherbuliez, E. Helv. Chim. Acta 1932, 15, 464.

23. Pettit, G. R.; Ode, R. H.; Coomes, R. M.; Ode, S. L. Lloydia 1976, 39, 363.

24. Fuhrman, F. A.; Fuhrman, G. J.; Nachman, R. J.; Mosher, H. S. Science 1981, $212,557$.

25. Verheyden, J. P. H.; Moffatt, J. G. J. Org. Chem. 1972, 37, 2289.

26. Rosemeyer, H.; Toth, G.; Golankiewicz, B.; Kazimierczuk, Z.; Bourgeois, W.; Kretschmer, U.; Muth, H. P.; Seela, F. J. Org. Chem. 1990, 55, 5784.

27. Davis, J. T.; Tirumala, S.; Jenssen, J. R.; Radler, E.; Fabris, D. J. Org. Chem. 1995, 60, 4167.

28. Anzai, K. Agr. Biol. Chem. (Tokyo) 1976, 40, 373.

29. Uzawa, J.; Anzai, K. Can. J. Chem. 1985, 63, 3537.

30. Still, W. C.; Kahn, M.; Mitra, A. J. Org. Chem. 1978, 43, 2923.

31. Chen, G.-S.; Chen, C.-S.; Chien, T.-C.; Yeh, J.-Y.; Kuo, C.-C.; Talekar, R. S.; Chern, J.-W. Nucleosides Nucleotides Nucleic Acids 2004, 23, 347. 